\title{
¿Y CÓMO HABITAMOS? \\ Una Aproximación al concepto de lo fundante \\ en Heidegger
}

\author{
Por: Claudia Benito
}

\section{Resumen}

Este escrito está dividido en tres momentos: en el primero, se muestra de manera general por qué Heidegger considera que el humanismo es otra metafísica, o mejor, que todo humanismo se ha fundamentado metafísicamente. De ahí surge la necesidad del giro, de la KEHRE, para buscar lo verdaderamente fundante. El segundo, examinará la idea de la ciencia moderna como lo fundamental de la existencia y si

Claudia Benito es Filósofa de la Universidad del Rosario, magistra en filosofía de la Universidad Javeriana, estudiante de maestría en Antropología Social de la Universidad de Los Andes; actualmente es docente investigadora del Departamento de Filosofía y Centro de Estudios e Investigaciones Humanas y Sociales de realmente es ella lo más fundante de la existencia humana. El último se refiere a la reflexión sobre lo que Heidegger considera el verdadero habitar como lo fundante.
Abstract
This piece is divided in three phases: the first evaluates in general terms why Heidegger considers that humanism is another metaphysics or that all humanism was metaphy- sically established; from this the KHERE theory emerges consecutively to explore the fundamental requirements. The second phase studies the concept of modern science as the vital element of existence and, if in fact, it is the most vital element for the human existence. The last phase refers to Heidegger's notion of a true dwelling. 
Esta parte del escrito está dividido en tres momentos: en el primero, se muestra de manera general por qué Heidegger considera que el humanismo es otra metafísica, o mejor, que todo humanismo se ha fundamentado metafísicamente. De ahí surge la necesidad del giro, de la KEHRE, para buscar lo verdaderamente fundante. El segundo, examinará la idea de la ciencia moderna como lo fundamental de la existencia y si realmente es ella lo más fundante de la existencia humana. El último se refiere a la reflexión sobre lo que Heidegger considera el verdadero habitar como lo fundante.

Para Heidegger, "Todo humanismo, o sea el romano, y todas las especies de humanismo que han aparecido desde entonces hasta el presente, presuponen la "esencia" más general del hombre como evidente." El hombre, que según la tradición es concebido como animal racional, está en el centro de la pregunta por el hombre que hace la metafísica, el problema está en que "La Metafísica representa, ciertamente, al ente en su ser y piensa así el ser del ente. Pero no piensa la diferencia entre los dos". La metafísica piensa al hombre desde el animalitas no lo piensa hacia la humanitas. El humanitas se traslada al ser del ente y se trata de definir al humanitas por lo que tiene de ente, así la pregunta por el ser es la pregunta por el ente - existe porque está - es determinable, existente, es lo que está siendo por fuera, ecsistente, su historia es la historia del ente.
El humanitas romano, jurídico- legal, cobija hoy al hombre y al humanismo, habitando la norma, adhiriéndose a ella y legitimándose por una ley externa, con el máximo desarrollo de la razón en occidente, fluyendo además en saturación de información, la humanitas nos ha llevado paradójicamente al irracionalismo; en este sentido podemos decir que ahora la palabra humanismo perdió su sentido, y, por tanto, la filosofía del humanismo también lo perdió. Pareciera entonces que se hace necesario recuperar el humanismo. "Todo humanismo o se funda en una metafísica o se hace a sí mismo fundamento de una metafísica ${ }^{1}$... [Pero] Cada vez más se pasa por alto la esencia y, ciertamente, con motivo del mismo proyecto metafísico."2

Heidegger en la Carta sobre el humanismo, hace un doble apartamiento; se aparta del existencialismo sartriano, considerándolo un "ismo" más de la metafísica; y se aparta también de su propia reflexión comprendida antes en "Ser y Tiempo" por considerarla que no iba más allá del humanismo metafísico.

El lenguaje de la analítica del ser en el mundo ("Ser y Tiempo") no puede "Comprender" el dasein como relación (Verhältnis), la aproximación desde este lenguaje es un trabarse, enredarse y el olvido del ser es su consecuencia, nos encontramos así en la época del olvido del ser, en la época del proceder técnico, de la deshumanización.

${ }^{1}$ Heidegger, Martín. Carta a Jean Beaufret, Parisin 1959. (Carta sobre el humanismo) p.16

${ }^{2}$ Heidegger, Martín. Carta sobre el humanismo p. 20 
Para superar el olvido del ser, y por tanto la deshumanización que con él va emparentada, Heidegger se sitúa en contrariedad, cambia de rumbo, se encamina en el camino encosándose, produce un giro al interior de su pensamiento, la "kehre". Los puntos de partida ahora son la "experiencia” y el "decir"; la experiencia como "la relación" con las cosas, eliminando lo representado, así dilucida, señala-despojando; y el "decir" en copertenencia con la "experiencia”. Así pues, la "relación" de proximidad con el ser es el lugar donde el hombre es lo más cercano y el ente es lo más lejano. El hombre habita así en el lenguaje, tal como lo expresa con toda claridad el mismo Heidegger y el lenguaje no es otra cosa más, que la casa del ser.

El autor pasó de pensar un ser ocupadopreocupado de Ser, a uno que cuida el ser, y en ese cuidar se Gira, es el "Pastor del Ser". Este Pastor se deja conducir por la escucha del ser orientándose hacia su finalidad de Hombre mismo El "giro" es hacia el "pensar" en la senda de una adecuada interpretación del ser del ente, su historia y su época es la del abismamiento creciente de la pregunta por el ser. Si bien este problema implica ya un distanciarse de la metafísica de la subjetividad que caracteriza Ser y Tiempo, lo cierto también es que este giro, implica realmente buscar una relación más fundante del dasein en su propia historicidad esencial y con su facticidad estructural. El dasein habita en el lenguaje y este lo atraviesa en un modo fundamental.
Pero ¿cómo se ha dado este giro? Y ¿por qué se ha hecho necesario?, ¿cómo fue posible que se perdiera el hombre dentro de la pregunta de lo que es?

“El hombre más bien, está "arrojado" por el ser mismo a la verdad del ser, de tal manera que ec-sistiendo de tal modo, cuida la verdad del ser para que en la luz del ser aparezca el ente en cuanto el ente que lo es. Si él aparece y cómo aparece, si y cómo el Dios y los dioses, la historia y la naturaleza vienen, se presentan y se ausentan; sobre esto no decide el hombre. El advenimiento del ente descansa en la destinación del ser. Pero al hombre resta la pregunta de si él encuentra lo conveniente y lo destinante..."3

Tal vez el hecho más importante que se ha desplegado por la faz de la tierra con todo su poder a partir del siglo XVII es la emergencia de la ciencia moderna.

La ciencia no expresa solo un deseo del hombre por conocer, sino que ella es además algo diferente; esta "diferencia” reclama el desprendernos de nuestras representaciones habituales que tenemos de ella e iniciar el Camino por un sendero que podría arrancar en la pregunta: ¿sobre qué fundamento descansa la esencia de la ciencia moderna?. La respuesta está en el habla. La palabra de este habla, contiene la historia de la experiencia de "mundo", de cada época, ella está

${ }^{3}$ Heidegger, M. Carta sobre el humanismo, p. 27 
compuesta de varios pisos geológicos sobre los cuales podemos ir descendiendo para descubrir la historia de la experiencia sensible que el hombre ha depositado en ella. La palabra es siempre un acaecer, un acontecido, que no cesa en su mutabilidad pero que guarda matices de los primeros rayos que la vieron nacer, en este camino descansa parte de la certitud del habla. "El aliento sobre la esencia de una cosa viene hacia nosotros del Habla." 4

La afirmación que responde a la pregunta sobre la esencia de la ciencia moderna es: "La ciencia es la teoría de lo real." Pero aquí no se nombra por ciencia a la que corresponde al período antiguo o medieval, sino a la que versa sobre la ciencia contemporánea. La esencia de la ciencia moderna, no obstante, hunde sus raíces en el pensar griego, aunque ello no se debe tomar como un cerco que impida reconocer lo peculiar del saber de la época moderna, el cual consiste en la elaboración radical de una forma de conocer experienciada ya en la esencia del saber griego.

La ciencia moderna encuentra la huella primigenia de su esencia en el diálogo, siempre presente, con el pensamiento griego elaborado por filósofos y poetas, pero sin implicar esto una especie de renacimiento tardío del mundo helénico. "En la proposición 'la ciencia es la teoría de lo real, lo pensado, lo destinado tempranamente permanece presente" ${ }^{5}$. Para aclarar ese sentido el

${ }^{4}$ Heidegger, Martín. Ciencia y técnica. Construir, habitar, pensar. Editorial universitaria. Santiago de Chile. 1933. p. 160

${ }^{5}$ Heidegger, Martín. Ciencia y Meditación. p.41 mismo Heidegger afirma, "Todo está únicamente en que la verdad del ser llegue al lenguaje y en que el pensar llegue a este lenguaje. Tal vez pide el lenguaje entonces mucho menos el precipitado esperar y más bien el justo llegar." ${ }^{6}$

Para continuar este camino debemos dilucidar lo que designa el nombre "lo real", avistando el horizonte en donde la palabra entra a "hablar", es decir, la región interior donde se mueve la cosa nombrada por la palabra. Lo que acontece en ella para poder designar lo acontecido. La palabra "real", nombra la cosa en su despliegue, habla con la trama de los significados donde lo nombrado por ella se abre en el acontecimiento del pensar y el poetizar de cada época.

"Obrar" significa "hacer", hacer es lo que obra, es lo presente en su presencia. Obra es como lo presente está "presente", obrar es un producir en la presencia. "Obrar es traer y producir ya sea porque algo desde sí, se produce en la presencia ya sea porque el hombre lleva a cabo el traer y producir de algo."7

El rasgo avizorado en el pensar griego que se constituye más tarde en la esencia de la ciencia moderna, es la actividad del hombre en cuanto tal: "traer y producir" este desocultar de lo ocultado, este traer al frente por sí. Lo real es la obra de lo traído ahí-delante a la presencia, la presencia consumada en sí de algo que se trae a sí delante. De acuerdo

${ }^{6}$ Heidegger, Martín. Ciencia y técnica. p.42

${ }^{7}$ Op. Cit. p.42 
con el carácter propio de la temporeidad de lo real la presencia es un perdurar; es un mantenerse en lo producido por el desocultamiento, es lo que se mantiene en la apertura de lo desocultado.

De acuerdo con la tradición esta apertura es llamada por Aristóteles la presencia de lo propiamente presente, expresión que se ha traducido por energeía. El latín hace de esta expresión, que designa la permanencia de lo traído adelante, como algo que resulta de una Actio. Lo real comienza a ser entonces lo conseguido, el objeto de una causa efficiens, donde lo conseguido en el hecho es lo real del hecho; entendiendo por hecho aquí el asegurar que comparte la misma categoría significativa de palabras como: seguro y cierto. Lo obrado es un conseguir que produce una cosa, que resalta un trabajo que permite establecer lo real. Lo real como un conseguir hace que lo presente llegue a una posición (stand) y que lo encontremos a él como tal posición, lo real se muestra ahora como el ob-jeto (Gegen-stand).

El pensar griego y el medieval no concibieron lo presente como objeto, por esta razón Heidegger prefiere llamar al modo de presencia de lo presente como obstancia. Esta será la primera opción del carácter de lo presente mismo. Ahora pasaremos a poner de manifiesto qué es lo que permite que lo real como objeto pueda ser representado y esto se aborda cuando recuperamos nuestra afirmación inicial: "La ciencia es la teoría de lo real” para entrar a examinar: ¿Qué es lo real con relación a la teoría? Esto implica que historiemos la trama de significaciones que filósofos en su dialogo con los poetas han fraguado en la palabra "teoría".

En griego a la palabra "teoría" le corresponde un significado alto y misterioso que designa lo que establece un modo de vida contemplativo que tiene en el pensar la forma más consumada de lo humano, pero un pensar en el puro respeto a los aspectos de lo presente, al hacer brillar la presencia de los dioses. En su sentido arcaico teoría es el mirar cobijante de la verdad. Este alto sentido permanece sepultado en términos tales como: La teoría de la relatividad, teoría atómica, etc. Cuando la palabra griega de la que nace el término teoría, es convertida en contemplation en la lengua romana y el terreno preparado por el pensar griego va produciendo sus resultados en Latín, se realiza en este tránsito el carácter separador e incisivo frente a lo que debe ser aprehendido en la vista y que reivindica su valor en el conocer. Este momento será el origen de lo que más tarde veremos como la imposibilidad de la obstancia por circundar la esencial plenitud de la naturaleza.

El término latino de contemplation es vertido en lengua alemana como Betrachtung, observación, contemplación y que podemos deslizarlo hacia la elaboración de lo real como un ponerlo a seguro, nos revela una actividad inquietante del hombre, la cual es su forma de establecer el fundamento de lo real mismo en la elaboración de este como poner a seguro. Lo real es confiado a un recinto de 
objetos por la teoría. Cada nuevo fenómeno que aparece en los límites de una ciencia es elaborado hasta que encaja en la trama objetual de la teoría, que se presenta como un fin, como algo que es objetuado si tiene un fundamento elaborado de antemano por la teoría pura, la cual hace entrar un fenómeno a un plano de legalidad para la ciencia, lo vuelve objeto. "la ciencia pone lo real." ${ }^{8}$ Max Planck afirma: "Real es lo que se deja medir". Esto es lo que decide para la física lo que puede llegar a ser conocimiento: la mensurabilidad. Toda objetualización de lo real es un contar, donde el lugar que ocupa la matemática es el de poner en todas sus partes, por medio de ecuaciones, el equilibrio a las relaciones de ordenamiento, que son uno de los fundamentos de este contar, para asegurar esa serie de objetos que produce la ciencia en su afán de ser "científica".

La ciencia moderna como teoría de lo real descansa también en el rango preeminente del método, donde se delimitan regiones de objetos, compartimentando cada una de ellas y vigilando sus fronteras. Cada región atribuye una particularidad a sus objetos, una ciudadanía, donde la exploración de cada región se convierte en especializada. Estas regiones de objetos dan origen a ciencias especializadas que las delimitan. Esta delimitación no es un rasgo que anuncie la decadencia de la Ciencia moderna sino que anuncia algo misterioso, tan misterioso como el fundamento de la ciencia moderna.

${ }^{8}$ Heidegger, Martín. Ciencia y técnica. p. 123
Miremos la diferencia entre la física clásica y la física atómica. Aunque ambas se basan en la pretensión de poner a seguro objetos desde la teoría, en la física atómica desaparece el objeto y ya no es una relación sujetoobjeto de la manera de la física clásica, sino que llega a su límite por ser emplazado el objeto en la estructura del emplazamiento, convirtiéndose así en algo existente al ser susceptible de ser solicitado. La física moderna no se limita a prepararle el camino a la técnica, sino a la esencia de la técnica: al emplazamiento provocador.
"Al emplazar y solicitar provocadores se les muestra aquello que es como lo "con- sistente"[existencia en plaza: Bestand]. "Por todas partes se solicita que se esté allí de una forma susceptible de ser solici- tada, con vistas a una solicitud posterior. Lo solicitado de este modo tiene consis- tencia [Stand] propia... La palabra consis- tente es pensada como título para el carácter del desocultar en que se muestra el ente como lo solicitado."9

La ciencia se expresa como la forma de legalidad de la naturaleza porque la emplaza a ser existente como objeto desde el llamado a ser de determinada manera en el cuantificar, pero la naturaleza es por sí misma sin ciencia. Aunque la física forme objeto del modo como ella lo convoca, no alcanza a cercar la plenitud esencial de la naturaleza. De este

${ }_{9}^{9}$ Pöggeler, Otto. El camino del pensar de Martin Heidegger. Alianza Universidad. 1986. p. 264 
modo la ciencia física acaba proclamando a la naturaleza como lo irrodeable.

Lo inabordable de la naturaleza permite poner en cuestión el modo como la ciencia se sitúa en la naturaleza y nos hace preguntarnos si acaso la ciencia misma está inhibida para meditar la esencia desde sí. La ciencia descansa en el estado de las cosas inadvertido como el río en su fuente. El viaje hacia aquello que es digno de ser cuestionado no es una aventura sino un regreso al hogar. Pero la ciencia no se encuentra con el problema de su incapacidad de abordar: "La plenitud esencial de la naturaleza", sino como un problema exterior a ella, no lo encuentra en su manera de convocarla. Habrá entonces que echar a andar en la otra direcciórı que percibió el pensamiento griego de la presencia de lo presente, no desde un convocar, sino desde sí, desde lo que por sí misma la cosa ha tomado la permanencia de lo presente. Lo que en alemán se dice meditar: "prestarse al sentido". La meditación abre un espacio donde se mide nuestro hacer y dejar hacer. La meditación es un camino donde lo fundamental vuelve a abrir sus puertas para ser cuestionado abandonando ese fijar de antemano que hay en las ciencias y en la cultura. La meditación nos lleva a la confianza de un morar en el camino que va por sí a lo que es de por sí la cosa, el término meditación...

"debe ser tomado en el doble sentido ya aludido. Aquí designa, por tanto, la acción de meditar (besinnen), pero también el comprometerse en la dirección del camino al atinar con la salida apropiada. Justo por ello la meditación debe encontrar un camino (Weg) incluso allí donde la presente situación aporética (ausencia de salida, callejón sin salida, Ausweglosigkeit) parece no encontrar salida (Ausweg) alguna."10

La meditación misma es entonces la serenidad para meditar lo digno de ser cuestionado, esto es lo que Heidegger llama el regreso al hogar. El regreso al hogar, no es otra cosa que volver a lo propio, es el retorno a la morada donde se es de manera propia, con apropiación, es decir, donde habitualmente somos, por lo tanto, la meditación estará encaminada a lo que habitamos y al modo cómo lo habitamos. Este pensar no se hará desde el arte de la construcción y de la Técnica, sino que retrotrae el construir al ámbito al que pertenece todo lo que es. Preguntamos:

1. ¿Qué es habitar?

2. ¿Hasta qué punto pertenece el construir al habitar? ${ }^{11}$

Construir y habitar no pueden pensarse separadamente. Cuando pensamos en el habitar descubrimos que ingresamos a él por medio del construir, y cuando pensamos el construir vemos que éste tiene como meta el habitar. $Y$ aunque no toda construcción es una habitación, por lo menos toda construcción tiene que ver con el ámbito de nuestro habitar, es por eso que aún en los sitios de

${ }^{10}$ Heidegger, Martín. Conceptos Fundamentales. Editorial Altaya. Barcelona. 1994 p. 123

${ }^{11}$ Heidegger, Martín. Construir, Habitar, Pensar p.159 
trabajo o sitios donde "habitualmente" estamos nos sentimos como en casa. ¿Cuál sería entonces la diferencia?. Dichas construcciones domicilian al hombre, pero sólo el hombre las habitúa y cuando lo hace ya no hablamos únicamente de poseer una habitación sino de habitarla. "Así el construir y el habitar están en mutua relación como medio y como fin." ${ }^{12}$ Sin embargo el construir no sólo es medio para el habitar "el construir es en sí mismo, ya habitar. ¿Y de dónde se nos da el conocer esa esencia de habitar y construir?

Otra vez, del habla misma. Y ¿cómo la descubrimos? Si prestáramos correcta atención en el habla misma. Pero el hombre ha olvidado que es el habla misma lo más elevado y se ha comportado como el formador y patrón de aquella, utilizando el habla como un simple medio al servicio de la expresión (habladuría). Volvamos entonces a la esencia de la palabra. ¿A qué se llama construir? “La palabra del alto alemán medieval para construir [bauen], (que también quiere decir campesino), “buan”, significa habitar. Esto quiere decir: permanecer, mantenerse. La significación propia del verbo construir se nos ha extraviado. Una huella encubierta ha sido conservada todavía en la palabra "Nachbar" [vecino]."13 Los verbos buri, büren, beuren, beuron, significan todos el habitar, el hogar." Habitar es un modo de comportarse junto a muchos otros. Construir quiere decir originariamente habitar y cuando hablamos origina-

\footnotetext{
${ }^{12}$ Heidegger, Martín. Construir, Habitar, Pensar p.160

${ }^{13}$ Heidegger, Martin. Construir, Habitar, Pensar p. 161
}

riamente sabemos al mismo tiempo hasta qué punto está lograda la esencia del habitar. “Bauen, buan, bhu, beo es, pues, la palabra alemana bin [soy] en los giros: ich bin[yo soy], du bist [tú eres], el imperativo bis [sé tú]. ¿qué significa entonces ich bin? La vieja palabra bauen, a la que pertenece "bin", nos responde "ich bin", "du bist" significa; yo habito, tú habitas. Es decir, el modo de ser y ser hombre quiere decir ser mortal sobre la tierra que quiere decir: habitar. $\mathrm{Y}$ habitar significa cultivar; cultivar es una forma de construcción que cuida lo que crece y da frutos; de esta manera cultivar es una forma de construcción auténtica, un edificar. Así queda el construir como habitar en el lenguaje como lo "habitual". Así la significación propia de la palabra construir, el habitar, cae en el olvido.

"Sin embargo, si nosotros oímos lo que el habla dice en la palabra bauen [construir], entonces percibimos tres cosas:

Construir es propiamente habitar. Habitar es el modo como son los mortales sobre la tierra. El construir como habitar se despliega en el construir que cuida, a saber, el crecimiento, y en el construir que edifica construcciones." ${ }^{14}$

Mientras no pensemos que toda construcción es un habitar, ni siquiera podremos formular la pregunta. Habitamos no porque hayamos construido, sino que construimos. $Y$ hemos construido cuando habitamos, esto es, en cuanto somos los habitantes.

${ }^{14}$ Heidegger, Martín. Construir, Habitar, Pensar p. 163 
Pero hasta aquí hemos hablado de la esencia del construir, ahora habrá que examinar "en qué consiste la esencia del habitar. Oigamos una vez más el aliento del lenguaje: la palabra del antiguo sajón “wown”, la gótica “wunian", significan igual que la vieja palabra bauen, el permanecer, el mantener-se. Pero la gótica "wunian" dice más claramente cómo es experimentado este permanecer. Wunian significa: estar contento, llevado a la paz, permanecer en ella. La palabra Friede [paz] mienta lo Freie [libre], lo Frye y fry significa custodiado de daño y amenaza, custodiadoante... , y esto es protegido... El proteger auténtico es algo positivo y acontece cuando, de antemano, dejamos algo en su esencia... El rasgo fundamental del habitar es este proteger. Así vemos que el ser del hombre descansa en el habitar y en el sentido de la morada de los mortales sobre la Tierra.

Sobre la tierra quiere decir bajo el cielo esto es, "permanecer ante los divinos" e incluye un "perteneciendo a la comunidad de los hombres". Por una originaria unidad copertenecen en uno los cuatro: Tierra y Cielo, los Divinos y los Mortales.

Cuando pensamos a cada uno de ellos copensamos a los otros tres pero no meditamos el despliegue-unitario de los cuatro.

La tierra es la portadora servidora. El cielo es la marcha abovedante del sol, luz y tinieblas. Los divinos son los mensajeros señalantes de la Deidad. Del sagrado imperar de ellos aparece el Dios en su presente o se retira en su embozamiento. Los mortales son los hombres, se llaman mortales porque tienen el poder de morir, Morir quiere decir: tener el poder de la muerte en cuanto muerte.

“ La tierra no es, empero, aquello que está a los pies del hombre ni el cielo lo que está sobre su cabeza, pues tierra y cielo no son en general nada que sea ente, sino"comarcas del mundo"... Cuando Heidegger llama mortal al hombre, ¿no será entonces necesario que sepa con seguridad quién es el hombre?... Y en lo tocante a lo divino, llega Heidegger a decir que quien, habiendo dejado madurar su experiencia desde el origen, sabe de teología, sea la de la fe o la de la filosofía, prefiere guardar silencio hoy sobre Dios en el ámbito del pensar. Si ello es así ¿qué puede significar entonces que hable aún de los [seres] divinos?"15

Para Heidegger la experiencia nietzscheana de la muerte de Dios es decisiva. Para él el dios experienciado en la historia acontecida occidental, determinada por la metafísica, está muerto. Incluso el dios moral es la elección equivocada de una humanidad que se niega a sí misma y a la vida. Cuando esta humanidad es superada, su elección de un dios moral queda igualmente refutada. Solamente cuando se abandona al dios metafísico, llega el pensar a quedar libre para el "Dios divino". Si Heidegger puede nuevamente plantear la cuestión de Dios se debe a que, según su experiencia, lo refutado es la esencia de Dios. Esencia que había sido

${ }^{15}$ Op. Cit. Pöggeler. P. 269 
pensada como el Ser por encima del ente, lo que lleva al ocultamiento y niega toda posibilidad del desocultamiento. Ahora el hombre en el pensar, transformado en su estar, se abre a la divinidad como lo espejeante del ser y así hombre y divinidad (dioses) ambos están, el uno frente al otro, posibilitando el acontecer. Esto es lo verdaderamente esenciante: el acontecimiento, el ereignes. El acontecimiento se hace entonces y definitivamente posible por el despliegue del cielo, la tierra, los divinos y los mortales.

A este despliegue lo llamamos la cuadratura o lo cuadrante. Los mortales son en lo cuadrante, habitando. Y como el rasgo fundamental del habitar es el proteger, los mortales habitan protegiendo el cuadrante en su esencia; así acogen la tierra en cuanto tierra, el cielo en cuanto cielo y esperan a los divinos en cuanto divinos.

El habitar como proteger guarece lo cuadrante en donde los mortales se mantienen: en las cosas. El habitar protege lo cuadrante, llevando su esencia a las cosas. Los mortales dispensan sumos cuidados a las cosas crecederas y a las cosas que no crecen las edifican propiamente. El cuidar y el edificar es el construir en cuanto es un guarecer.

“En la medida en que el riesgo arroja a lo arriesgado, también lo mantiene en la balanza. El riesgo libera a lo arriesgado de tal manera que lo arrojado no es liberado más que a una atracción hacia el centro. En virtud de esa atracción, lo arriesgado es prestado al centro. El riesgo recoge hacía sí una y otra vez a lo arriesgado en esa atracción." 16

“¿Pero hasta qué punto pertenece el construir al habitar? "la respuesta a esta pregunta nos aclara lo que propiamente es el construir, pensado desde la esencia del habitar."17

Si pensamos en el puente que oscila ligero y fuerte sobre el río, vemos que no une simplemente las orillas; el puente, con las orillas trae en cada caso al río, él trae río y orillas y país en la vecindad recíproca. El puente recolecta la Tierra como comarca en torno al río. El puente deja al río su curso, y al mismo tiempo, guarece para los mortales su camino, por el que andan y viajan de país en país. Así el puente conduce de camino en camino inclusive hasta llegar al último puente donde traspasa lo habitual y se queda ante la gracia de lo divino. El puente colecta, en cuanto el tránsito impulsante, frente a los Divinos. “El puente recolecta junto a sí a su modo, Tierra y Cielo, los Divinos y los Mortales. Según una vieja palabra de la lengua alemana recolección se dice "thing". El puente es y ciertamente, en cuanto la señalada recolección de lo cuadrante- una cosa [Ding]."18 Pero el puente no es sólo una cosa (en la concepción occidental pobre de la cosa), es una cosa de tipo peculiar; "pues recolecta lo cuadrante de manera tal que le localiza

${ }^{16}$ Heidegger. Martin. Caminos de bosque. ¿Y para qué poetas?. Alianza editorial. 1984.p. 254

${ }^{17}$ Heidegger. Martín. Caminos de bosque. p. 167

${ }^{18}$ Heidegger. Martín. Caminos de bosque. p. 169 
[verstattet] un paraje [Stätte]. Pero sólo por lo que él mismo es un lugar puede espaciar un paraje. El lugar no está ya ahí antes del puente. Ciertamente antes de que el puente esté, hay muchos sitios a lo largo del río que podrían ser ocupados por algo. Uno entre ellos se da como lugar y, por cierto, por el puente. Así, pues, el puente no llega a estar primeramente dentro de un lugar, sino que desde el puente mismo surge ante todo un lugar." Y las cosas que son lugar localizan espacios. Espacio se llama al sitio libre para la colonización y el lecho. Un espacio (como lo concibieron los griegos) es algo liberado, en un límite, donde el límite es aquello donde algo comienza su ser. En el ser de estas cosas como lugares yace el vínculo entre lugar y espacio, pero yace también la referencia del lugar al hombre, que se mantiene en él. Tendremos que analizar ahora ¿en qué relación están lugar y espacio? Y ¿cuál es la relación entre hombre y espacio?.

El puente es un lugar que en cuanto cosa localiza un espacio en el que son introducidos Tierra y Cielo, Divinos y Mortales. El espacio contiene distintos sitios que son localizables entre los que hay una distancia medible $^{19}$; una distancia, en griego stadion, está siempre espaciada por simples sitios. Lo espaciado por sitios es un espacio de tipo peculiar. El es en cuanto espacio un intervalo.

Los espacios que nosotros recorremos cotidianamente están espaciados por lugares; su

${ }^{19}$ Recordemos que esta condición de mensurabilidad es también esenciante de la ciencia moderna. ser se fundamenta en cosas del tipo de las construcciones. Si prestamos atención a estas referencias entre lugar y espacios, entre espacios y espacio, entonces ganamos un punto de apoyo para meditar la relación entre hombre y espacio.

Cuando decimos hombre, lo sabemos dentro de un espacio y al lado de las cosas. Los mortales habitando transportan espacios sobre el fundamento de su morada junto a cosas y lugares. El vínculo del hombre con lugares y, por medio de lugares, con espacios, estriba en el habitar. La relación de hombre y espacio no es otra cosa que el habitar esencialmente pensado. Si pensamos de esta manera la referencia entre lugar y espacio entonces tendremos claridad sobre la esencia de las cosas, que son lugares y que nosotros llamamos construcciones. El puente es una cosa de tal tipo. El lugar introduce el despliegue unitario de Tierra y Cielo, de los Divinos y los Mortales en un paraje, erigiendo el paraje en espacios. El lugar admite a lo cuadrante y el lugar erige a lo cuadrante. Así ambos en el doble espaciar se copertenecen. En cuanto al doble espaciar es el lugar una custodia [hut] de lo cuadrante o como dice la palabra Huis, una Haus [casa]. Cosas del tipo de tales lugares encasan [behausen] la morada de los hombres. El producir tales cosas es el construir, su esencia estriba en que corresponda al tipo de esas cosas. Estas son lugares, localizan espacios. Por eso el construir que erige lugares es un fundar y tramar espacios. Proteger a lo cuadrante, salvar a la Tierra, acoger al Cielo, 
esperar a los Divinos, conducir a los Mortales, este cuádruple proteger es la sencilla esencia del habitar.

La esencia del construir es el dejar-habitar. La realización de la esencia del construir es el erigir lugares por medio del tramar sus espacios. Sólo si nosotros tenemos el poder de habitar, podemos construir.

Se espera que por medio del intento de pensar el habitar y el construir se haga más claro cómo el construir pertenece al habitar y cómo recibe su esencia de él. Así construir y pensar son indispensables para el habitar. El siguiente paso sería formularnos la pregunta ¿qué pasa con el habitar en nuestro tiempo? Aún más, en nuestro tiempo de penuria? La auténtica penuria del habitar consiste en que los mortales tendrían que buscar nuevamente la esencia del habitar, en que ellos tendrían que aprender ante todo a habitar. $Y$ eso sólo se lograría si construyen por el habitar y piensan en el habitar. "Permanezcamos, también en los días venideros, en el camino como peregrinos de la vecindad del ser." 20 Es decir, en el acontecer.

La comprensión del acontecer no puede ser más clara en el texto de Heidegger titulado ¿Por qué permanecemos en la provincia? ${ }^{21}$ uno de los más hermosos y, pienso yo, completamente consecuente con toda su filosofía; no podría

${ }^{20}$ Heidegger, Martín. Carta sobre el humanismo. p.43

${ }^{21}$ Heidegger, Martín. ¿Porqué permanecemos en la provincia? ECO Revista de la cultura de occidente \#35 Tomo VI 5 . Marzo de 1963
“En una abrupta cuesta de un amplio y alto valle de la Selva Negra se levanta un pequeño refugio de esquiadores a 1.150 m. de altura sobre el nivel del mar. Su planta mide de 6 a 7 metros. El bajo techo recubre tres cuartos: la cocina, el dormitorio y un gabinete de estudio. En el estrecho fondo del valle y en la ladera opuesta, igualmente abrupta, yacen dispersos los cortijos de los campesinos, ampliamente emplazados, con el gran techo que pende sobre ellos. Cuesta arriba se extienden las praderas y dehesas hasta el bosque con sus viejos, enhiestos y oscuros abetos. Todo lo domina un claro cielo soleado en cuyo resplandeciente espacio dos azores se elevan trazando círculos." 22

Heidegger más que permanecer en la provincia, en la tierra natal, en la serenidad.

La hermosa descripción con la que Heidegger comienza su escrito, nos pone ya en camino para la comprensión de su filosofía, del verdadero acontecer. Basta con que empecemos a recorrer los elementos que componen este paisaje. Antes que nada aparece la Selva Negra, el bosque, que tiene varias dimensiones. Por un lado la Selva está al lado de la cuesta, del abismo y por otro lado, la selva contiene árboles y campesinos, todo dominado por un cielo soleado por donde se elevan dos aves.

\footnotetext{
${ }^{22}$ Heidegger, Martín. ¿Porqué permanecemos en la provin-
} cia?. p. 472 
Miremos, pues, lo primero: La selva al lado de la cuesta. Estos dos elementos son la clave en el giro del pensar heideggeriano, la cuesta que representa el abismo [abgrund] que es el fondo, el lugar donde se encuentra la modernidad debido a su desarraigo, a su falta de raíces, un fondo sin fundamento; pero también está la Selva que se alza hacia el cielo echando sus raíces al suelo, es pues, la Selva la representación de lo que funda: echar raíces y crecer tendiendo hacía lo alto.

El segundo elemento: árboles y campesinos, lo más representativo de la tierra, quienes más la conocen y quienes la cuidan, quienes la oyen, quienes son porque la tierra es, quienes la nombran y a quienes ella nombra, por lo tanto la fundadora.

El tercer elemento: el cielo con aves que pueden volar en su espacio. El cielo, imagen de lo que se alza sobre árboles y campesinos y por supuesto sobre la tierra, y cielo como lo opuesto al abismo. ¿Y las aves? las únicas capaces de volar por el cielo, las únicas que siendo habitantes de la tierra son capaces de elevarse por encima de ella, ¿Y qué podría representar aquella imagen de las aves que sobrevuelan la tierra? no podría ser otra cosa que los poetas, capaces de conservar su vínculo con la tierra y al mismo tiempo capaces de acercarse al cielo, pasando incluso sobre el abismo.

Para quien lee desprevenidamente la carta de Heidegger pensará que se trata de una hermosa descripción de caracter rural; que fundaría lo que se suele llamar una ontología agraria; perc cuan lejos está de imaginar el gran contenido que nos ofrece: la cuadratura del Ser, que no consiste en una simple teoría o en una simple reflexión, va mucho más allá, está ligada con la vida misma con el modo de ser de los entes ya no como un paradigma sino como siendo.

Y después de esta descripción aún nos dice Heidegger que ésta sería la visión de su "mundo de trabajo visto con los ojos mirones del huésped “23. ¡ Cuántas cosas aún nos faltan entonces por comprender! Bien, pero sigamos nuestro análisis y pongamos nuestra mirada sobre la misma frase que nuevamente nos dice Heidegger: los ojos mirones del huésped. ¿Y acaso no tiene razón Heidegger? ¿cómo podríamos entenderle o ver más allá si sólo somos huéspedes? ¿ si no somos habitantes de esta tierra, ni siquiera vecinos? ¿si no tenemos raíces en ella? y por lo mismo sólo podríamos mirar las cosas con ojos de extrañeza. Esta extrañeza significa que no podemos "ver las cosas", mucho menos nombrarlas adecuadamente.

Para que pudiéramos lograr esto tendríamos que darle su lugar al habla, tendríamos que dejar que el habla hablara para que se pudiera lograr el trazo abriente del habla, del habla en cuanto decir. El trazo abriente nos revela la relación entre hablante - hablado y - lo no hablado. Pero el Decir no es un punto de

${ }^{23}$ Heidegger, Martín. ¿Porqué permanecemos en la provincia?. p. 472 
llegada: hablamos el habla, hablamos desde el habla, pero también oímos el hablar del habla, así, el habla nos dice su decir y el escuchar se convierte en un dejar-se-decir, este dejar-se-decir implica el silencio que hace posible el escuchar; pero nada de esto tendría sentido si el escuchar y el habla no fueran de carácter apropiador, si no mostraran las cosas como cosas encosadas, es decir, no en su forma oculta de simple cosa, sino precisamente en su desocultamiento y más estrictamente en el desocultamiento de su ser. Todo esto imposible para los ojos del extraño, porque los ojos del extraño no alcanzan a ver el movimiento, sólo ven una aparente quietud, no alcanzan a distinguir en el paso de los días y las noches la transformación continua del paisaje, no alcanzan a distinguir el acontecer del paisaje.

Pero esto no lo logra el visitante porque no está en verdadera cercanía con la tierra “ $\mathrm{Al}$ hombre de la ciudad una estadía en el campo, como se dice, a lo más “estimula'”. ${ }^{24}$ Así el visitante jamás podría darse cuenta de todo esto, jamás podría escuchar a la tierra porque está muy lejos de ella, no la trabaja, no la cultiva y por lo tanto no la habita. "Habitar es el modo como son los mortales sobre la tierra". 25

El vínculo del hombre con lugares y, por medio de lugares, con espacios, estriba en el habitar. La relación de hombre y espacio no

\footnotetext{
24 Heidegger, Martin. ¿Porqué permanecemos en la provincia?. p. 473

${ }^{25}$ Heidegger, Martín. ¿Porqué permanecemos en la provincia?. p. 474
}

es otra cosa que el habitar esencialmente pensado. "Así la marcha del trabajo permanece en el acontecer del paisaje." ${ }^{26}$

Pero aún nos queda muchísimo más:

"Cuando en la profunda noche de invierno una bronca tormenta de nieve brama sacudiéndose en torno del albergue y oscurece y oculta todo, entonces es la hora propicia de la filosofía. Su preguntar debe entonces tornarse sencillo y esencial. La elaboración de cada pensamiento no puede ser sino ardua y severa. El esfuerzo por acuñar las palabras se parece a la resistencia de los enhiestos abetos contra la tormenta." ${ }^{27}$

No sólo estamos en el desarraigo, hay aún otro elemento que nos aleja de lo esencial: una noche llena de tormenta que oscurece todo. La penumbra en la que la modernidad se encuentra, donde a pesar de ofrecer la posibilidad de una existencia total Ilena de confort, dominada por la técnica, que lo único que hace es engañar sobre el control absoluto de las cosas volcando todo a un simple manejo o manipulación, volviendo todo utensilio y ocultando por ende su esencia.

${ }^{26}$ Heidegger, Martín. ¿Porqué permanecemos en la provincia?. P. 475.

${ }^{27}$ Heidegger, Martín. ¿Porqué permanecemos en la provincia?. P. 475 


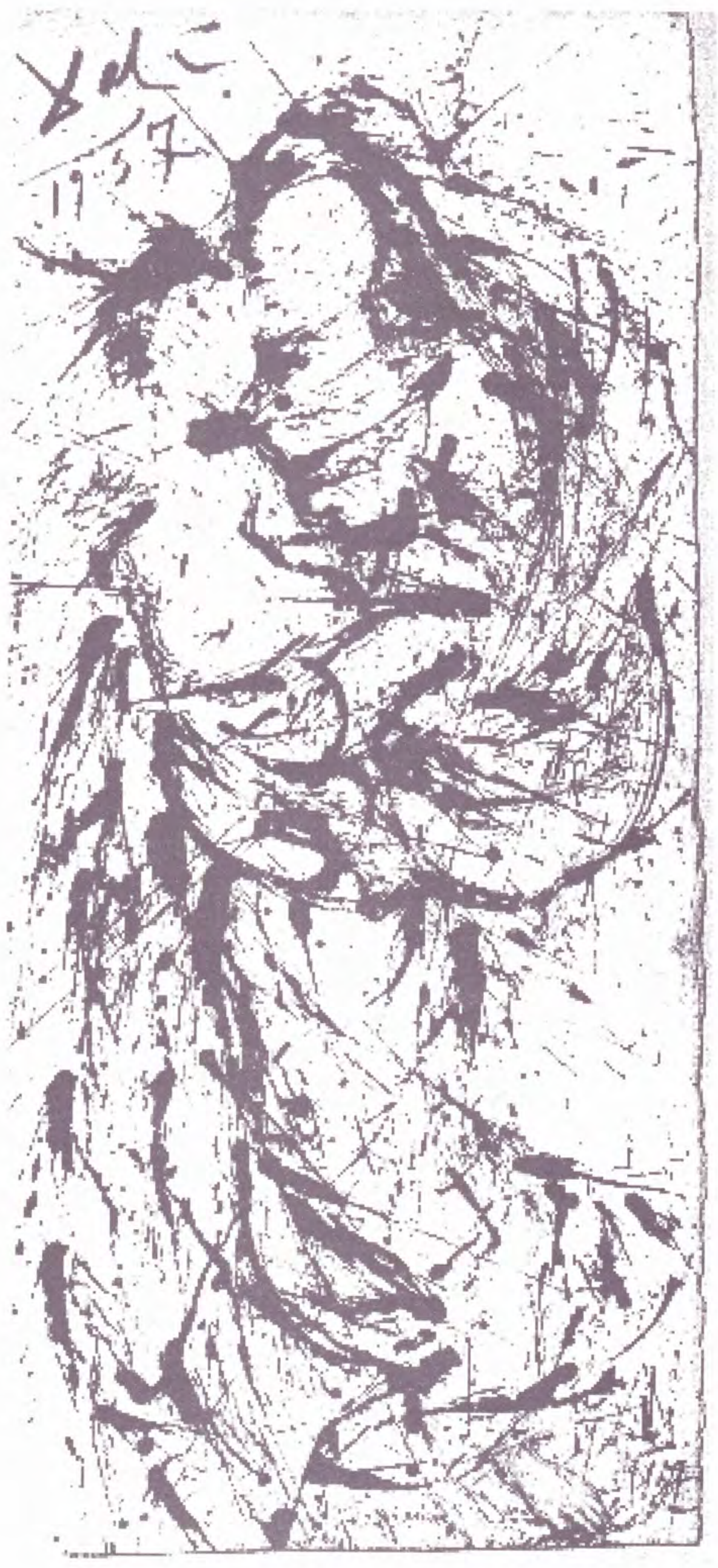


Sólo cuando por fin, en medio de la oscuridad y la tormenta de la noche podamos permanecer en reposo, podremos nuevamente elaborar la pregunta por lo esencial. $Y$ debemos tener en cuenta que en la noche en que nos encontramos, en la penuria de la noche, lo único que en este momento nos es posible es la reelaboración de la pregunta por lo esencial, "porque el aliento sobre la esencia de una cosa viene hacia nosotros del habla."

Sin embargo, no se trata del simple preguntar, se trata del preguntar que debe estar en íntima relación con lo buscado, es decir, con la tierra, con lo que funda, por eso el preguntar ( la filosofía ) será un esfuerzo arduo de superación del abismo, del subir la cuesta, al igual que el trabajo del campesino en la Selva Negra.

No hace falta entonces perderse entre las

"La íntima pertenencia del propio trabajo a la Selva negra y a sus moradores, viene de un centenario arraigo suabo-alemán a la tierra que nada puede reemplazar." 28

cosas, o en la Selva, simplemente hay que "estar a solas" con ellas y en esto radica la auténtica soledad: "pues la auténtica soledad tiene una fuerza primigenia que no nos aísla, sino que arroja a la existencia humana total en la extensa vecindad de todas las cosas." ${ }^{29}$

${ }^{28}$ Heidegger, Martín. ¿Porqué permanecemos en la provincia?. p. 476

${ }^{29}$ Heidegger, Martín. ¿Porqué permanecemos en la provincia?. p. 476
Así el campesino vive en la vecindad de su tierra, y vecindad quiere decir dejando ser su tierra y ser desde la tierra. No en vano el puente une orillas en un traerles en vecindad reciproca. 